\title{
Application of Anchor Spray Combine Arch Rib Reinforce Technology of Stone Arch Bridge
}

\author{
Fang Ruiwei, a and Yang Xiuzhi, ${ }^{2, b}$ \\ ${ }^{1}$ School of Transportation, Wuhan University of Technology, Wuhan 430063, China \\ ${ }^{2}$ Linyi Road Bureau, Linyi 276000, China \\ áfangruiwei@whut.edu.cn, ${ }^{b} 1371455096 @ q q . c o m$
}

Keywords: Stone arch bridge; Arch rib; Anchor spray; Reinforcement technology.

\begin{abstract}
With the development of bridge construction in China, disease bridges became more and more, bridge reinforcement became a important topics facing the bridge workers. Shi-Yan line (S335) Shuigou Bridge is a stone arch bridge of 5-20meter, diseases such as stone arch ring crack, break, endanger the bridge operations seriously, in order to ensure bridge structure stable, enhance its carrying capacity, save money, improve effectiveness, using anchor spray combine arch rib reinforce technology strengthen this bridge. The author point out that set arch rib in original arch ring, between ribs anchor sprayed concrete, this construction technology is not only to overcome the construction difficult and large self weight of traditional method of set full arch ring, but also overcome the disadvantages of bad bearing capacity of overall bolt and shotcreting technology. It can be used for repair reinforcement and reconstruction of stone arch bridges and concrete arch bridge.
\end{abstract}

\section{Introduction}

Shuigou Bridge is a stone arch bridge which built in 1976, limited by the technical conditions and funds, the design standard is low and the construction quality is poor. With the increasing of overloading and traffic volumes, the bridge is no longer to suit today's economic development needs and serious diseases such as cracks, broken in arch ring seriously endanger the operating safety of bridge, so effective technical measures must be taken. Demolition and reconstruction is the best policy to exclude security vulnerabilities, but consider highway maintenance fund, road traffic guarantee, integrity of old and new bridges, security, and so on, demolition and reconstruction is not the best option. In practical work, we needed to find a good method that use little money, low equipment requirement, ensure the old and new bridges stable, improve the bearing capacity of bridge, and need not to close traffic for a long time. Through demolition and reconstruction, reinforcement of arch rib, bolting and shotcreting three strengthening technology scheme selection, Shuigou Bridge adopt anchor spray combine arch ribreinforce technology end. Pour rib wall on abutment wall, bond rebus and pour arch rib on inner edge of arch ring, intercostal planted rebar mesh and shotcrete, ribbed wall, arch, anchor-shotcrete layer and the original structure form a whole to attain the purpose of reinforcement.

Shuigou Bridge at K210+900 of the province road of Shi-Yan line(S335), the upper structure of the left old bridge is 5x20meter arch bridge, the original design load is Grade 20 of automobile, built in 1976 , the width of bridge is 8.2 meter, the main arch ring is made of mortar masonry stone, the vector-cross ratio is $1 / 8$, the lower structure is masonry stone gravity-type piers and abutments, asphalt concrete pavement on the bridge deck. The new bridge is 5x20 meter stone arch bridge, built in 2006, the lower structure is pile foundation, masonry stone gravity-type piers and abutments, asphalt concrete pavement on the bridge deck, the design load is Grade 20 of automobile and Grade 100 of trailer. The new bridge and old bridge split joint directly, unified packing on the arch, paved two layer cement stabilize broken stone of 36centimeter with two layer bituminous concrete surface course of 7 centimeter. After splice, the new bridge and old bridge is operating as Grade 20 of automobile. The bridge is completed in 2007, the full width of bridge is 16 meter, the net width of bridge pavement is 15 meter. 


\section{Design Scheme of Reinforcement}

According to the regulation of "Code for Maintenance of Highway Bridges and Culvers (JTG H11-2004)," [1], through the bridge regular inspection in 2009, we found that the main arch ring vault of old bridge has serious transverse crack, the biggest width of crack is 0.35 millimeter, the longth of crack is 7.5meter, the vault of no.5 hole arch axis is downwarp, arch ring are all seepage serious, much mortar between stone falls off, the overall quality degradation is serious. The main arch ring deformation cause vault displacement and craze, on the left of the arch ring of no.3, no.4, no.5 hole, the joint of cladding stone and flank wall craze at the vault area, the longest crack area reach 6 meter; The asphalt concrete pavement all appear transverse run-through crack in each pier roof. Routine inspection assesses, the new bridge is 2 kind of bridge, the old bridge is 4 kind of bridge, and suggested that the old bridge demolish rebuild or repair reinforcement.

Through more design scheme selection, the main arch ring of the old bridge of Shuigou Bridge adopt anchor spray combine arch rib method to reinforce. Strengthening design load level according to the current bridge calculating load level road- II level [2], equivalent to the original bridge design specification Grade 20 of automobile. The design scheme is: the main arch ring add 5 reinforced concrete arch ribs with its interval is 105 centimeter, thickness is 30 centimeter, width is 80 centimeter, between ribs set 5 diaphragm with its thickness is 30 centimeter, width is 30 centimeter, which located at vaults, 1/4, 3/4 and arch feet. The grid between the ribs and the diaphragms hanged rebar mesh, reinforcing rebar is $\varphi 12$ millimeter, interval is 10 centimeter, anchor bolt spray 10 centimeter concrete. The corresponding position on the arch feet to the new arch rib on every abutment add 5 cast-in-situ concrete ribs wall with thickness of 30centimeter and width of 80centimeter to support arch ribs, the width of the edge of the old bridge is 40 centimeter, and the rib wall with its thickness 30centimeter can be directly located on the edge of the pier platform; between the pier rib wall set 2 beams, which located below the arch feet 1.15 meter and 2.15 meter, between the abutment rib wall set 3 beams, which located below the arch feet 0.15 meter, 1.35 meter and 2.85 meter, both of the width and the thickness of the beam is 30 centimeter. After reinforcement, rib wall, arch rib, anchor bolt spray mesh and the original bridge structure form a whole bearing stress together.

Anchor spray combine arch rib method pour concrete rib wall on the edge of the piers, its arch ring inner edge bonded rebar pouring 5 arch ribs, between ribs implant rebar mesh and sprayed concrete, rib wall, arch ribs, anchor bolt spray layer and original structure form a whole bearing stress together, to improve its stiffness, and suppress the arch ring crack effectively, achieve reinforcement, improve the bearing capacity of bridge [2]. The method is little difficulty in construction, the equipment is simple, the cost is low, the construction period is short, the effect on the traffic is small. Compared to demolish rebuild this method can save resources, protect the environment effectively, and does not polluting rivers.

\section{Construction Craft of Anchor Spray Combine Arch Rib Method}

The construction craft of anchor spray combine arch rib method for Shuigou Bridge: close to traffic, rib wall and beam construction, set up support, seal crack of arch ring and cut hair, arch rib and beam construction, intercostal mesh section anchor spray, clean up the field and open traffic.

Close to Traffic. To reduce the effect of the traffic load on the concrete construction, the traffic on the left of the bridge should be closed during the construction of rib wall, arch rib and anchor spray. According to the regulation of "Safety Work Rules for Highway Maintenance (JTG H30-2004)," [3], set standard and complete sign of construction work, load and speed limit, warning and so on, arrange specially-assigned person responsible for traffic control, to ensure the construction quality and safety of construction personnel and pedestrian.

Rib Wall and Beam Construction. Lofting according to the design drawing layout, each pier place 5 rib wall line and 2 beam line, each abutment place 5 rib wall line and 3 beam line. Drilling hole in the facade at the position of rib wall and beam per 50-60 centimeter distance drilling, the depth of hole is 10 centimeter, pour plant rebar glue into those hole, implant $\varphi 16$ millimeter rebar into pier, 
erect rib wall and rebar skeleton of beam. Erect vertical formwork at laterality of the rib wall, but the formwork over against facade can not erect once in place, first make half of the formwork, leave part convenient for pouring concrete and vibrate dense, then join height vertical formwork successively to pouring concrete up until the final section is poured complete.

Set Up Support. Set up support to meet the need of arch rib construction and anchor spray construction, set full support by steel pipe down each hole. Each support adopt $4 \varphi 48$ millimeter steel pipe which wall thickness is 3.5 millimeter for upright, support structure adopt $100 \times 100$ square centimeter or $100 \times 200$ square centimeter plane, set the same specification steel pipe as cross and slant supports every 2 meters height, steel tube is connect by the buckles, adjust the support height properly according to the construction need. The complete full support is shown in Fig 1. Before setting construction, draw support construction blueprint, through the strength and stability checking, materials and support can satisfy the construction stress and load requirements, ensure support strength and stability.

Seal Crack of Arch Ring and Cut Hair. The arch ring crack of the old bridge which width over 0.2 millimeter adopt grouting closed treatment [4]. First remove laitance and dust within the scope about 50 millimeter near the cracks, and cut the sealing mouth into v-shape that wide 0.5 centimeter, remove the ashes and sands of the sealing mouth, and scrub by the cotton yam with acetone, embed into grouting mouth. Use epoxy mastic close the v-shape mouth, and then pressure grouting against to grout mouth, until the crack is full with potting glue.

After closing the cracks, polishes the arch ring surface with grinding wheel, cleares surface floating dust, laitance, peel, forms a certain roughness on the surface.

Arch Rib and Beam Construction. Lofting, plant rebar and set up skeleton. The process is same with the construction of ribs wall. Erect formwork and obligate $6 \times 6$ centimeter hole on side plate to convenient for vibrating. Open hole and pour C30 concrete. the arch ribs and beams after this construction are shown in Fig 2. Seal hole with concrete to prevent water enter and obligate 7 centimeter asphalt concrete layer downward the surface of bridge deck.

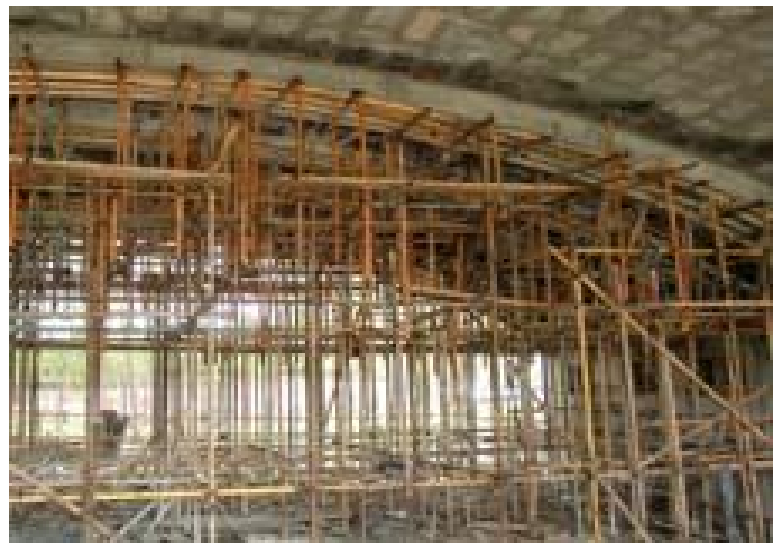

Fig. 1 Full support

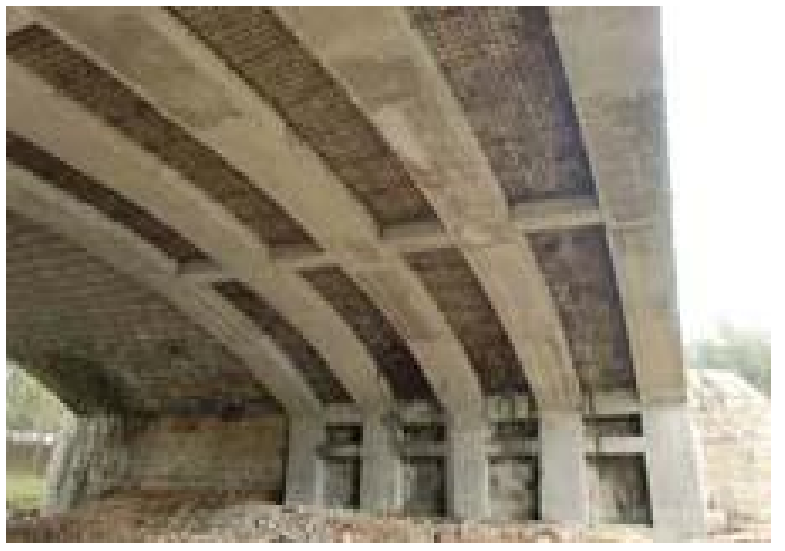

Fig. 2 Arch rib and beam

Intercostal Mesh Section Anchor Spray. Implant $\varphi 12$ millimeter and 5 centimeter deep rebar in gridding, winkle rebar that precast when pouring arch ribs and beams, make it welding firm with main rebar, layout into rebar mesh, main and deputy rebar are all $\varphi 12$ millimeter, spacing is 10 centimeter, the net thickness of protective layer of rebar mesh is 3 centimeter.

Table 1 Weight mix proportion

\begin{tabular}{|c|c|c|c|c|c|}
\hline Material & Cement & Sand & Gravel [5 10mm] & $\begin{array}{c}\text { Acceleration } \\
\text { agent }\end{array}$ & Water \\
\hline Code & M1 & M2 & M3 & M4 & M5 \\
\hline Ratio & 1.00 & 1.92 & 1.92 & 0.04 & 0.04 \\
\hline
\end{tabular}

The bridge adopt C30 spray concrete, the design of weight mix proportion is shown in table1, control the slump between 90 millimeter to 120 millimeter, the sand coarse aggregate ratio is $50 \%$. 
The bridge adopt dry spray construction method. When inject, the distance from spray nozzle to spray face is about 60 to 80 centimeter, the direction of the injection is vertical with the spray surface, spray gun screw rotate clockwise on the spray surface, the spiral diameter is $20 \sim 30$ centimeter, in order to make the spray concrete dense. Spraying concrete is dark gray, moist, luster, no spot or sliding flow phenomenon. The spray thickness is 10 centimeter and spray in three times.

After initial setting of finally spray concrete layer, scrap excess material outside the 10centimeter line with scraper, and spray decorate or wipe a layer of mortar. After final set 2 hours, water spray maintain, the maintain time is not less than 14 days, ensure the strength to form.

Clean Up the Field and Open Traffic. After the completion of the anchor spraying, dismantling support, clean up construction waste below bridge, levelling the ground below the bridge. Arch ribs and anchor spray concrete maintain expires, remove bridge construction mark etc, and open traffic in time.

\section{Matters Need Attention in Construction}

Reinforcement of bridges in danger is different from the visuality and order of construction of new bridges. Especially the reinforcement of Shuigou Bridge adopt set arch rib method combine anchor spray method in construction. In construction we should pay more attention to the control of key links and key parts, do details in place.

Pay Attention to the Joint of Rib and Beam. When construction, pay more attention to the joint of vertical rib wall and beam, the joint of lengthways arch rib and beam. We should use iron sheet reinforce formwork, vibrate concrete carefully, and adopt other measures to make the vertical and horizontal joint smooth.

Open Hole in Vault with Cautious. Because that the arch rib is under the arch ring so that we can not pour concrete after erect formwork, the best method is to drill hole at vault to smooth pouring. But, the integrity of arch ring made of stone is poor, it is easy cause damage when drilling and endangering the old arch ring security, so we had better not or less open hole. When we have to open hole, be careful, avoid strong vibration, the diameter should as small as possible, not in the same line and recover in time after pouring.

Control the Slump of Arch Rib Concrete. When construction, pour arch rib is very difficult, we should control the concrete proportions strictly, especially control the concrete slump, timely detection according to standard frequency, completes the concrete test pieces. When pour completed, strengthen the maintenance of concrete .

Construct According to the Technical Parameters of Anchor Spray Strictly. When concrete anchor spraying, construct accord to the design mix proportion strictly, pay attention to jet distance and direction, jet order and color of concrete, control the thickness of the injection, make spray surface level and optimum.

\section{Evaluation of Reinforcement Effect}

Evaluation of Economy. The reinforcement of Shuigou Bridge costs about 1.04 million RMB, while the demolition of the original arch bridge and rebuilding a 5-20 meter reinforced concrete hollow slab bridge need about fund 2.46 million RMB, compared with demolish rebuild, reinforcement save money about 1.40 million RMB, the economic effect is remarkable.

Evaluation of Function. When the reinforce construction finished, the bridge is under a identify and appraisal acceptance by Bridge Test Center of Shandong province. Through the checking computations of cross-section strength and stability of main arch ring, both of cross-section strength and stability of combined section after reinforcement satisfy the load level required (Table 2). After the reinforcement of the bridge the increase dead load of each pier is $13.5 \%$ and it is less than standard allow value [2], bridge pier foundation bearing capacity can satisfy the design load level requirements ( Table 3). 


\section{Summary}

The stone arch bridges that strengthed by anchor spray combine arch rib method have good performance characteristics, the integrity and durability of the bridge improve notable [5]. The technology need less construction machine and equipment, short construction period and low cost [6]; Don't damage the bridge structure and not endanger the safety of new bridge and not ruining the environment, it can maintain normal traffic, bring small effect to people's travel. Compared to demolish rebuild, this method conservation resources, reduce the waste of materials, no pollution and accord with low carbon environmental protection concept. Therefore, anchor spray combine arch rib method for stone arch bridge reinforcement, whether in technology or economic, has an important meaning, it is worth to further widely used in reinforcement of stone arch bridge and concrete arch.

Table 2 Checking computation table of strength and stability of main arch rib after reinforcement

\begin{tabular}{|c|c|c|c|c|c|c|}
\hline \multirow{2}{*}{$\begin{array}{l}\text { Control } \\
\text { Section }\end{array}$} & \multicolumn{3}{|c|}{$\begin{array}{l}\text { Checking Computation of Cross Section } \\
\text { Strength }[\mathrm{Kn}]\end{array}$} & \multicolumn{3}{|c|}{ Stability of Main Arch Ring [m] } \\
\hline & $\begin{array}{l}\text { Load } \\
\text { combination }\end{array}$ & $\begin{array}{l}\text { Section } \\
\text { resistance }\end{array}$ & $\begin{array}{l}\text { Whether } \\
\text { satisfy }\end{array}$ & $\begin{array}{l}\text { Distance of } \\
\text { shaft centers }\end{array}$ & $\begin{array}{l}\text { Allow } \\
\text { eccentric }\end{array}$ & $\begin{array}{l}\text { Whether } \\
\text { satisfy }\end{array}$ \\
\hline vault & 2690 & 3675 & Yes & 0.085 & 0.237 & Yes \\
\hline $\mathrm{L} / 4$ & 2690 & 3675 & Yes & 0.137 & 0.237 & Yes \\
\hline $\begin{array}{c}\text { Arch } \\
\text { springing }\end{array}$ & 2690 & 3675 & Yes & -0.267 & 0.312 & Yes \\
\hline
\end{tabular}

Table 3 Dead load of component of pier and superstructure before and after reinforcement (Single pier)

\begin{tabular}{|l|l|l|l|l|l|l|}
\hline \multicolumn{2}{|l|}{$\begin{array}{l}\text { Dead Load Before Reinforcement } \\
{[\mathrm{Kn}]}\end{array}$} & $\begin{array}{l}\text { Value Added After } \\
\text { Reinforcement }[\mathrm{Kn}]\end{array}$ & $\begin{array}{l}\text { Add Ratio } \\
\text { of Dead } \\
\text { Load }\end{array}$ & $\begin{array}{l}\text { Allow } \\
\text { Value }\end{array}$ & $\begin{array}{l}\text { Conclusi } \\
\text { on }\end{array}$ \\
\hline $\begin{array}{l}\text { Superstructur } \\
\text { e }\end{array}$ & $\begin{array}{l}\text { Single } \\
\text { pier }\end{array}$ & $\begin{array}{l}\text { Gross } \\
\text { weight }\end{array}$ & Added value & $\begin{array}{l}\text { Added } \\
\text { ratio }\end{array}$ & $\begin{array}{l}\text { Allow } \\
\text { ratio }\end{array}$ & $\begin{array}{l}\text { Whether } \\
\text { satisfy }\end{array}$ \\
\hline Vault & 2690 & 3675 & Yes & 0.085 & 0.237 & Yes \\
\hline
\end{tabular}

In case that the base area not change, the vertical load added value of pier or abutment increase ratio is consistent with the added value of foundation stress.

\section{References}

[1] Ministry of Transport of the People's Republic of China: Code for maintenance of highway bridges and culvers (JTG H11-2004) (China Communications Press, Beijing 2004).

[2] Ministry of Transport of the People's Republic of China: Specincations for strengthening design of highway bridges (JTG/T J22-2008) (China Communications Press, Beijing 2008).

[3] Ministry of Transport of the People's Republic of China: Safety work rules for highway maintenance (JTG H30-2004) (China Communications Press, Beijing 2004).

[4] Ministry of Transport of the People's Republic of China: Technical specincations for strengthening construction of highway bridges (JTG/T J23-2008) (China Communications Press, Beijing 2008).

[5] Y.T. Zhou, W.G. Bao, Y.F. Liu, J.F. Jia and J.W. Zhao: Bridge Construction, Vol. 6( 2010), p.49-52.

[6] Z.M. Liu: Bridge engineering handbook of maintenance \& repair (China Communications Press, Beijing 2004). 